УДК 658.64

DOI: $10.14451 / 1.202 .164$

\title{
ПЕРСПЕКТИВЫ РЕАЛИЗАЦИИ КОНЦЕПЦИИ МАРКЕТИНГА ОТНОШЕНИЙ НА ПРОМЫШЛЕННЫХ РЫНКАХ
}

\author{
(c) 2021 Семенова Светлана Викторовна
}

Кафедра менеджмента и маркетинга, соискатель

Белгородский государственный национальный исследовательский университет, Россия, Белгород

E-mail semenova_sv@mail.ru

В данной статье раскрыты вопросы реализации стратегических и тактических задач, связанных с возможностями, которые предоставляет маркетинг для промышленной фирмы. Актуальность применения концепции маркетинга отношений в бизнес-практике промышленных предприятий обусловлена потребностью обеспечения эффективного их развития в новых условиях глобализации, ужесточения конкуренции, ускорения научно-технического прогресса, изменения требований и поведения организаций-потребителей, снижения эффективности традиционных маркетинговых подходов, роста ожиданий со стороны общества относительно качественного влияния каждого предприятия на формирование стабильного общеэкономического развития государства. Так как промышленные деятели больше развивают отношения с партнерами (клиентами, поставщиками, посредниками), чем действуют на рынке, то они должны быть готовы вкладывать инвестиции в развитие и поддержание этих партнерских отношений, используя инструменты маркетинга взаимодействия.

Ключевые слова: промышленный маркетинг, маркетинговые коммуникации, маркетинг взаимодействия, рынок $b 2 b$, партнерские отношения, конкуренция, клиентоцентричность.

\section{Введение (Introduction)}

Нынешние потребители избалованы предложениями. Если еще лет 50-60 назад людям приходилось выбирать, сходить в магазин через улицу или поехать на другой конец города, то теперь они буквально окружены торговыми точками. Если еще лет 20 назад агрессивный маркетинг работал, то теперь покупатели с огромной вероятностью откажутся от знакомства с компанией, которая звонит по три раза в день, чтобы рассказать об очередной акции. Современный маркетинг - это маркетинг осторожности, ненавязчивости и лояльности. Пожалуй, единственный способ не потеряться на рынке - найти «своих» и активно работать с ними.

Изменение человеческого поведения приводит к изменениям в бизнесе на всех уровнях. Получается, что сейчас происходит полное переосмысление подхода к стратегическому (да и тактическому) планированию бизнеса через включение технологического трека в процесс планирования. Может ли какая-то отрасль или компания остаться островком стабильности в этом океане изменений? Очевидно, нет. Сфокусированность на технологиях приводит компании к перестройке всей бизнес-модели. Выигрывает тот, кто лучше понимает клиента и может более гибко подстраиваться под его потребности.

Среда обитания человека стремительно изменяется. Становится ли жить легче или сложнее - риторический вопрос. Вполне закономерный вопрос сейчас - успевают ли привычные маркетинговые концепции за изменениями в поведении потребителей? Кто инициирует появление новых маркетинговых моделей - потребитель или продавец? И, конечно, главный вопрос: что делать?

Пандемия, охватившая весь мир в 2020 году, ударила по разным сферам жизни. Ее последствия ощутили на себе все: от малого до крупного бизнеса, как в сфере оказания услуг, так и в сфере промышленного производства. Никто не был готов к подобным событиям, перевернувшим жизненный уклад всего мира, и поэтому пути решения рыночных проблем, которые постоянно появляются на фоне нарастания пандемии, приходится находить быстро и мыслить нестандартно.

В рамках Synergy Marketing Forum - крупнейшего online-форума по маркетингу - прошел прямой эфир с Филипом Котлером. В конце своего выступления он подытожил: «Если в течение 5 лет вы в том же бизнесе, что и сейчас, то 
у вас нет бизнеса. Мир меняется и нужно уметь меняться вместе с ним». Это была самая мощная фраза, которая прошла красной нитью на протяжении всего «World marketing summit - 2020». И это он говорил не про компанию, а про состояние в общем - бизнес-модель, процессы, стили управления, инструменты и так далее.

Чтобы компания была успешна в будущем нужно уже сейчас, обучаясь у потребителя, строить гибкую систему маркетинга. Это значит не приравнивать потребителя под свои метрики, а реально понимать, чего он ожидает - то есть бизнес должен быть готов пересматривать свои операционные показатели под выявленные инсайты, готов переходить на новый маркетинговый уровень - уровень «тесных» отношений.

\section{Методы (Materials and Methods)}

В настоящее время наблюдается изменение и уровневый рост функционала маркетинга от товарно-сбытовой деятельности к управленческой и кооперационно-коалиционной. C учётом этого наивысший на сегодня тип маркетинга - это маркетинг взаимоотношений - инновационная технология работы промышленного предприятия с заказчиками на рынке, которая основана на максимальной вовлечённости будущего потребителя в процесс создания требуемого продукта.

Маркетинговая философия в XXI веке так или иначе должна проникать в стратегическое видение руководства всех предприятий, в том числе и промышленных Желающий оставаться на плаву бизнес должен соответствовать тому маркетинговому укладу, который актуален на сей день, и если завтра этот уклад разворачивается в другую сторону - бизнес должен повернуться с ним вместе.

Промышленный маркетинг - маркетинг товаров и услуг, которые закупаются через предприятия, учреждения и организации с целью их непосредственного или опосредствованного использования для производства других товаров и услуг.

То обстоятельство, что промышленный сектор должен соответствовать маркетинговым канонам, что маркетинг становится необходимым функционалом руководства производственных компаний, обусловлено негарантированным сбытом, требованиями ужесточающейся конкуренции, потребностями и условиями новой (по отношению к плановой) модели хозяйство- вания. Однако современные концепции маркетинга не означают только лишь выявление, изучение и удовлетворение тех потребностей, которые лежат на поверхности. Такие «стандартные» потребности как приемлемая цена и усредненное качество, а также сервисное обслуживание давно перестали быть козырями в руках предприятий-продавцов. Тем более, маркетинг в нынешней его интерпретации не тождественен продвижению товара на рынок или проталкиванию его любой ценой. Такой классический подход исчерпал свои возможности, что отмечается большинством авторитетных ученых и опытных практиков в данной области. Маркетинг в таком толковании является для предприятий, в том числе и промышленных, высокозатратным и рискованным [1].

Современные промышленные предприятия в своей маркетинговой деятельности должны учитывать динамику рыночных детерминантов, принимать в расчет возможности современной цифровизирующейся и турбулентной экономики и ее среды. В современных рыночных, культурных, социальных, а также экологических условиях необходим некий интегральный подход. Такой подход должен учитывать не только базовые потребности клиентов, которые и так лежат на поверхности и которые они декларируют в качестве основных, или основанные на информации, полученной от конкурентов, но и социальные аспекты. Дуальные отношения «производитель - заказчик» и трансакционный маркетинг, охватывающий 4Р, дополняются сейчас новыми инструментами, методиками, новыми участниками, представляющими интересы общественности. Методически концепция маркетинга взаимоотношений также строится на «Р»- элементах, но они приобретают более объемный и многомерный характер, обеспечиваясь не только непосредственными производителями, но также и партнерами, инвесторами, потребителями (они все могут быть представлены одним лицом).

Интересным и эвристически богатым аспектом концепции маркетинга отношений в промышленности может выступать теория компромиссов (между производителем и потребителем, между инвестированием и сбережением, риском и уровнем дохода, между менеджментом и персоналом и так далее). На наш взгляд, ключевые положения концепции маркетинга отношений могут служить эффективным и инновационным 
подходом к разработке инструментария маркетинга для современного промышленного предприятия.

Промышленность по определению означает тесную связь с понятием промыслительности (или предопределенности). Иными словами, при организации промышленного производства, которое требует значительных долгосрочных инвестиций, необходимо предвидеть целесообразность таких вложений и оценивать вероятность длительного успеха на том или ином рынке с товаром, услугой, деятельностью фирмы в целом. Цель такой промыслительности - обеспечить конкурентоспособность как возможность приносить доход, который, в свою очередь, появляется при условии развития долгосрочных отношений, достижения компромисса между продавцом товара и его покупателем - договоренности по цене, объему, качеству, срокам и т.д. Если стороны пришли к обоюдному соглашению, сделка состоится, и наоборот. Это же в известной мере свидетельствует о конкурентоспособности предприятия (продавца). Управление конкурентоспособностью на промышленном рынке сегодня является важнейшей функцией развития бизнеса, предприятия. Оно включает инструменты и способы воздействия на факторы конкурентных преимуществ и формы их реализации в практике осуществления ключевых идей концепции маркетинга отношений.

Выбираемая модель системы управления конкурентоспособностью промышленного предприятия - во многом результат маркетинга, формирования комплекса элементов «4Р» и более, исходя из результатов анализа рынка, прежде всего, потребителей и конкурентов. Она нацелена на определенный уровень конкурентоспособности за счет тех или иных факторов: особенностей товара, ценовой политики, продвижения, персонала и пр. Иными словами, за счет способности достигать компромисса между потребителями и промышленниками. Цель маркетинга отношений на промышленных рынках - достигать обозначенного рыночного компромисса быстрее и с большей степенью вероятности. При обосновании такой концепции маркетинга следует учесть, что ее использование промышленными предприятиями предполагает ряд допущений, а именно:

1) формирование потребительского спроса происходит одновременно с созданием продукта, а в некоторых случаях с опережением;
2) у каждого промышленного предприятия существуют сильные и слабые стороны, внутреннего и внешнего плана;

3) каждое предприятие способно создать уникальное торговое предложение, если сотрудничает с потребителем;

4) управление предприятием состоит из множества маркетинговых решений - от мелких, оперативных, до крупных - стратегических. Для того, чтобы эти решения были эффективными, необходим не только тщательный анализ вариантов решения, взвешенная оценка их последствий, финансовое и кадровое обеспечение, но и коммуникативная основа для принятия потребительских решений;

5) био-технико-социо-экономическую систему, каковой является промышленное предприятие, следует изучать объект, формирующий и приобретающий набор определенных качеств и характеристик, на основе которых он имеет возможность удовлетворять общественные потребности на основе построения долгосрочных отношений [2].

Анализируя определения промышленного рынка и специфические особенности маркетинга на промышленных рынках, приходим к выводу, что на первый план в промышленном маркетинге выходят деловые взаимоотношения. Основные виды деятельности, которые охватывает рынок ТПН: добывающая, обрабатывающая, строительство, транспорт, коммунальное хозяйство, связь, сельское и рыбное хозяйства, сфера услуг, банковская, финансовая и страховая деятельность, другие области. Отличия ТПН представлены на рисунке 1.

То, что деятельность на промышленном рынке отлична от аналогичной на рынке товаров народного потребления, очевидно. Но не всегда и, что греха таить, далеко не все специалисты - маркетологи понимают и осознают эти особенности. Итак, ключевыми особенностями, которые отличают промышленный маркетинг от потребительского, является природа потребителя и то, как он использует товар. В промышленном маркетинге потребителями являются организации и операции осуществляются с продукцией именно промышленного назначения.

На промышленном рынке маркетинговая работа заключается не в том, чтобы что-то продать, основная цель здесь - это заключение долговременных партнерских отношений, обеспечение взаимовыгодного сотрудничества. Промышлен- 

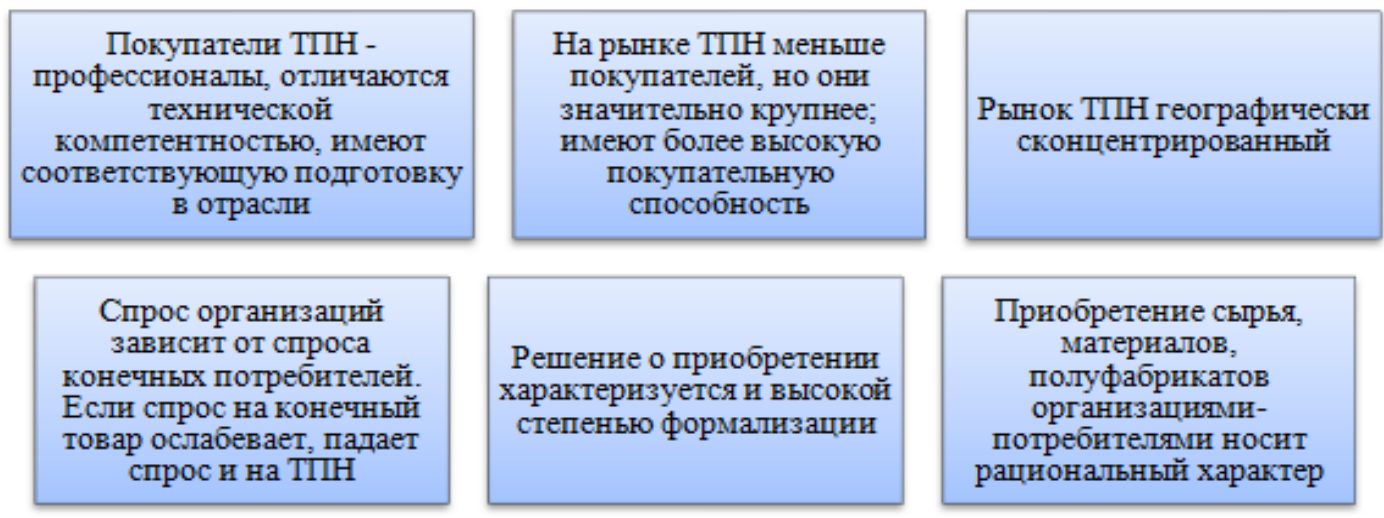

Организации-потребители нередко покупают товары на конкурсных торгах и торговьх переговорах.
Спрос на товары ТПН характеризуется низкой ценовой эластичностью

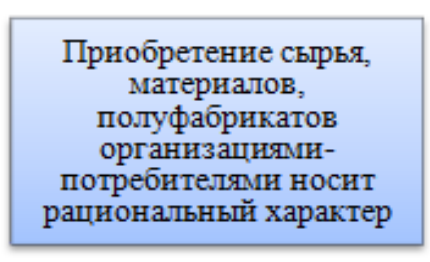

ТПН характеризуются значительной сложностью, технической комплектностью
Каналы сбыта ТПН, как правило, менее короткие: одно - или двухуровневые
Высокая степень взанмосвязи между покупателями и продавцами - организациями на рынке TПН

\section{Рисунок 1. Особенности товаров промышленного назначения [12]}

ные предприятия продают бизнесу не просто товар, а какую-то выгоду, пользу. На промышленном рынке нельзя просто ожидать появления клиентов, их нужно искать. Искать тех субъектов рынка, которых заинтересует ваше предложение, налаживать с ними стратегически важное коммуникационное взаимодействие.

\section{Результаты (Results)}

Такие факторы как глобализация мирохозяйственных связей, либерализация экономики, усиление конкуренции между компаниями за потребителей лишь давали стимул для развития концепции маркетинга взаимоотношений. Основная идея данной концепции состоит в том, что объектом управления маркетингом промышленного предприятия становятся коммуникации с покупателем и другими участниками процесса купли-продажи на промышленном рынке. Продукты все больше становятся стандартизированными, а услуги унифицированными, что актуализирует прогрессивность концепции маркетинга взаимодействия (маркетинга отношений). В этом случае единственный способ удержать потребителя - это индивидуализация отношений с ним, которая возможна на основе клиентоцентричного подхода, развития долгосрочного обоюдно выгодного взаимодей- ствия. Качественное партнерство - это не только снижение рисков, экономия ресурсов и улучшение финансовых показателей, но и гарантия долгосрочного существования промышленного предприятия.

Использование инструментов маркетинга взаимоотношений обеспечивает следующие преимущества для промышленного предприятия и для его клиентов (рис. 2):

Следует понимать, что концепция маркетинга партнерских отношений - это стратегия, а не тактика. Эта стратегия направлена на перемещение концентрации усилий по реализации отдельных продуктов к обслуживанию, где клиенту на промышленном рынке отведена самая важная роль - роль вершителя судьбы предприятия, где он осуществляет контролирующую функцию, определяет векторы развития предприятия.

Внедрение клиентоцентричного подхода требует изменений корпоративной культуры и психологии сотрудников промышленного предприятия, перестройки ключевых бизнеспроцессов. Если, к примеру, промышленное предприятие собирается предложить рынку новую продукцию, то потребитель отреагирует положительно в том случае, если ему предоставлена информация о технических характеристиках 


\section{Преимущества для промышленного предприятия}

- достигается снижение издержек, особенно связанных с привлечением Клиентов;

- у компании растут число и сумма покупок, поскольку постоянные потребители увеличивают расходы по возрастающей ставке, и итоговая прибыль превышает скидки этой категории потребителей. Потеря такого сегмента - потеря высокой прибыли;

- обеспечивается наличие ключевой группы потребителей, которая предоставляет фирме рынок

для тестирования и выведения новых продуктов или предложений с меньшим риском,

благодаря чему уменьшается неопределенность для фирмы в целом;

- выстраивается барьер для входа конкурентов на рынок за счет удержания стабильной базы потребителей, кроме того, стабильная база удовлетворенных потребителей является залогом удержания персонала фирмы.

\section{Преимущества для клиента}

- тесное взаимодействие с компанией, которое приносит психологические выгоды (потребитель общается с постоянными сотрудниками, ему не приходится каждый раз привыкать к новым людям);

• получение социальных выгод (установление дружеских отношений с персоналом промышленного предприятия);

• взаимодействие с фирмой, которое дает и экономические выгоды (получение скидок, рассрочки и т.п.);

• приспособление поставщиком услуги под конкретного потребителя за счет долгого сотрудничества

Рисунок 2. Преимущества применения концепции маркетинга отношений в практике промышленного предприятия [17]

товара своевременно и в полном объеме. Если потребителю продукт более или менее знаком, главным в его продвижении выступает уверенность в необходимости осуществить покупку, для чего следует добиться благоприятного отношения потребителя к продукции предприятия. Если товар или услуга уже надоели покупателю, то время от времени нужно подчеркивать их положительные черты.

К принципам маркетинга взаимоотношений, складывающихся на промышленном рынке, можно отнести следующие (рис. 3):

Наиболее важные функции предложения продукции на промышленном рынке, согласно постулатам маркетинговой концепции взаимодействия, следующие:

- создание на рынке образа престижности промышленного предприятия и его продукции в глазах контрагентов;

- информирование о показателях качества, технических параметрах и свойствах производимой продукции;

- сохранение популярности существующих и создание новых изделий предприятия;

- убеждение потребителей переходить к более ценным товарам;

- информация о ярмарках, распродаже и ответы на вопрос всех заинтересованных;

- обеспечение послепродажного обслужи- вания изделий;

- обоснование потребителю цен товаров и услуг;

- создание благоприятной информации о предприятии и его продукции относительно конкурентов и др.

Управленческая задача руководства промышленного предприятия, которое работает на основах маркетинга, состоит в ориентации на производство только тех товаров, в которых есть потребность на рынке. Деятельность предприятия может опираться на целиком очерченные принципы, а именно:

- ориентиром функционирования предприятия может стать не эпизодическая выгода, результат, а цели долгосрочного порядка, что дает возможность предприятию занять значительное место на рынке;

- предприятие должно не только приспосабливаться к требованиям рынка, запросам покупателя, а и активно влиять на них.

Клиентоцентричность для промышленного педприятия сегодня - это непременное условие существования и процветания. Стратегия, ориентированная на решение задачи клиента и перестройку бизнес-процессов компании под это решение - видимо, единственный способ оставаться конкурентоспособными в эру быстро развивающихся технологий. 


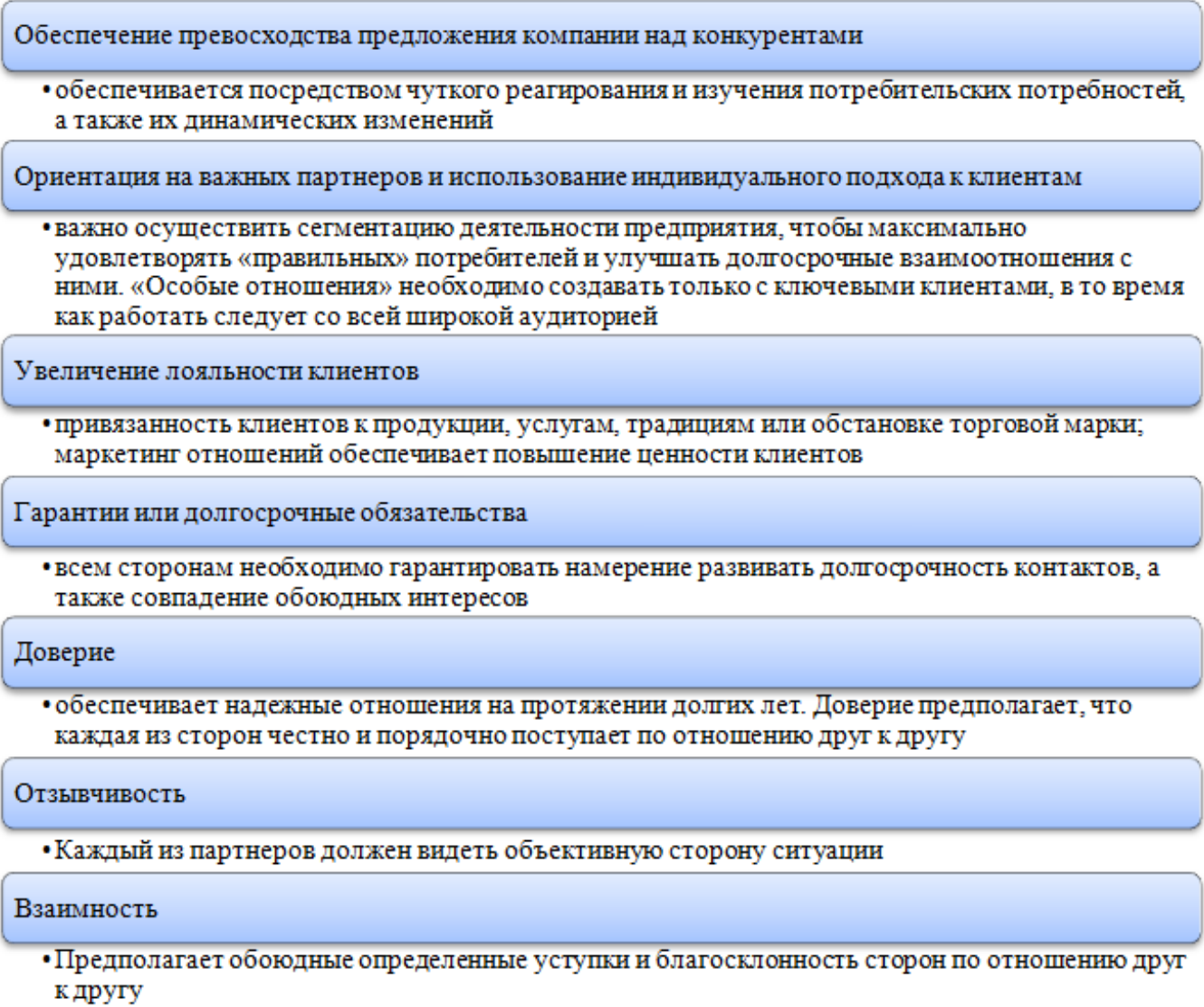

\section{Рисунок 3. Ключевые принципы построения маркетинга взаимоотношений} на промышленном рынке [17]

\section{Заключение (Conclusion)}

Таким образом, можно сделать вывод, что промышленный маркетинг является важным компонентом в системе производства и реализации продукции. Конечным результатом маркетинга партнерских взаимоотношений является построение уникальных нематериальных активов компании - маркетинговой деловой сети.

В деятельности промышленного предприятия в зависимости от специфики и системы управления, а также особенностей функционирования, маркетинг может играть разную роль. В частности, маркетинг может рассматриваться как равноправная, важнейшая, координирующая и направляющая, интегрирующая функция управления. Тем не менее, несмотря на роль функции маркетинга, в связи с динамичностью потребностей потребителей управление деятельностью промышленного предприятия должно быть цикличным, что дает возможность оперативно отслеживать изменения конъюнктуры рынка и вносить соответствующие коррективы в стратегию и тактику деятельности предприятия.

Поскольку маркетинг отношений олицетворяет собой определенную бизнес-философию, то те компании, которые активно используют данную систему, получают следующие преимущества:

- выстраивание барьера для конкурентов, который устанавливается за счет поддержки стабильной аудитории удовлетворенных покупателей;

- уменьшение издержек, которые несет промышленное предприятие для привлечения новых клиентов;

- формирование ключевой группы покупателей, которая позволяет фирме тестировать и выводить на промышленный рынок новые предложения с меньшими рисками;

- значительный рост покупок как в натуральном, так и в денежном выражении.

В условиях развития современной рыночной среды маркетинг отношений способствует формированию уникального актива для промышленного предприятия, обеспечивая рост 
прибыли и увеличение аудитории постоянных клиентов компании.

Глобальная задача маркетинга взаимоотношений - построение долгосрочных отношений с обоюдной пользой. Процесс продаж в клиентоцентричной компании - это не битва за лучшие условия, а диалог с клиентом о том, как вы можете помочь ему в достижении мечты. Сделайте этот диалог простым, открытым и вдохновляющим для клиента. Уже неоднократно доказано, что качественный сервис - это один из ключевых факторов, который непосредственно влияет на решение клиента остаться с вами надолго и возвращаться к вам снова и снова. Не нужно забывать и про то, что новые процессы не принесут ожидаемых результатов, если они осуществляются людьми, которые привыкли делать все по-старому. Поэтому важным фактором при реализации клиентоцентричной стратегии будет развитие персонала компании.

\section{Библиографический список}

1. Bondarenko V.A., Ivanchenko O. V., Mirgorodskaya O. N., Demyanchenko N. V. Role of staff marketing in increasing business performance // European Research Studies Journal. 2017. T. 20. № 3. C. 320-325.

2. Бондаренко В.А. Ключевая роль персональной компоненты в инфраструктурных и управленческих трансформациях // Менеджмент в России и за рубежом. 2006. № 6.

3. Бондаренко В. А. Апология маркетинга в кризисных условиях // Маркетинг в России и за рубежом. 2010 . № 4. C. 3-9.

4. Бондаренко В.А., Иванченко О.В. Вопросы формирования информационно-коммуникационной инфраструктуры маркетинга на основе исследования потребностей целевых сегментов (на примере локального рынка) // Конкурентоспособность в глобальном мире: экономика, наука, технологии. 2017. № 2-3 (31). С. $22-26$.

5. Бурмистрова И.К., Кублин И.М. Особенности влияния индикаторов структурных сдвигов на деятельность предприятия // Вестник Саратовского государственного социально-экономического университета. 2016. № 3 (62). С. 7-11.

6. Воронов А.А., Валькович О.Н. Факторы и методы измерения конкурентоспособности машиностроительных отраслей и регионов в современных условиях хозяйствования // Машиностроитель. 2004. № 4. С. 18-22.

7. Воронов А.А., Глухих Л. В. Стратегические коммуникации в системе управления промышленностью России // Практический маркетинг. 2007. № 8 (126). С. 7-13.

8. Воронов А.А., Катичев Ф.В. Маркетинговая концепция управления на предприятиях Кубани // Маркетинг. 2005. № 1 (80). С. 80-84.

9. Гарьковенко В.Э. Теоретические аспекты исследования стейкхолдер-менеджмента // В сборнике: ХХХ Международные Плехановские чтения. Сборник статей аспирантов и молодых ученых. 2017. С. 97-99.

10. Григорьева Е.А., Демьянченко Н.В., Фоменко Е.В. Построение системы менеджмента бизнеса промышленных организаций // Вестник ИМСИТ. 2015. № 4 (64). С. 9-11.

11. Демьянченко Н.В., Саргсян В.Р., Стадник А. М., Карпунина С. С. Задачи анализа конкурентных преимуществ организации // Сфера услуг: инновации и качество. 2019. № 40. С. 41-49.

12. Капустина Л. М. Развитие и применение концепции маркетинга взаимоотношений на промышленном рынке / Л. М. Капустина, Н. Б. Изакова // Журнал экономической теории. - 2018. - Т. 15. - № 2. - С. $240-253$.

13. Каратыш В.Э. Механизм стратегического планирования конкурентного развития предприятия // Сфера услуг: инновации и качество. 2017. № 30. С. 6.

14. Каратыш В.Э., Удовик Е. Э. Роль институционального фактора малого и среднего бизнеса в развитии региональных экономических систем. Краснодар, 2019.- 148 с.

15. Кублин И. М. Маркетинг в системе управления конкурентоспособностью продукции // Поволжский торговоэкономический журнал. 2013. № 2 (30). С. 52-60.

16. Махметова А.Е., Кублин И. М., Тинякова В. И. Методологические аспекты реализации процессного подхода в системе менеджмента качества промышленного предприятия // Экономика и предпринимательство. 2016. № 3-2 (68). С. 674-679.

17. Понятие и особенности промышленного маркетинга / В.Е.Довбыш, Т. С. Попова, И. В. Мишагина, И.А. Блужин // Экономика устойчивого развития. - 2020. - № 1(41). - С. 58-62.

18. Сысоева Т.Л. Особенности маркетинга взаимоотношений с поставщиками на промышленном рынке / Т. Л. Сысоева, М. Г. Зимина // Управленец. - 2014._- № 6(52).- С. 49-53. 